\title{
Article \\ Compartmental Learning versus Joint Learning in Engineering Education
}

\author{
María Jesús Santos $1,2, *,+\left[\right.$, Alejandro Medina ${ }^{1,2,+}$, José Miguel Mateos Roco ${ }^{1,2,+}$ a and \\ Araceli Queiruga-Dios $2,3,+(\mathbb{D}$ \\ 1 Department of Applied Physics, Faculty of Science, University of Salamanca, 37008 Salamanca, Spain; \\ amd385@usal.es (A.M.); roco@usal.es (J.M.M.R.) \\ 2 Research Institute on Fundamental Physics and Mathematics, University of Salamanca, \\ 37700 Salamanca, Spain; queirugadios@usal.es \\ 3 Department of Applied Mathematics, School of Industrial Engineering, University of Salamanca, \\ 37008 Salamanca, Spain \\ * Correspondence: smjesus@usal.es \\ + These authors contributed equally to this work.
}

check for updates

Citation: Santos, M.J.; Medina, A.; Mateos Roco, J.M.; Queiruga-Dios, A. Compartmental Learning versus Joint Learning in Engineering Education. Mathematics 2021, 9, 662. https:// doi.org/10.3390/math9060662

Academic Editor: Antonio Rodríguez Fuentes

Received: 1 February 2021

Accepted: 17 March 2021

Published: 20 March 2021

Publisher's Note: MDPI stays neutral with regard to jurisdictional claims in published maps and institutional affiliations.

Copyright: (c) 2021 by the authors. Licensee MDPI, Basel, Switzerland. This article is an open access article distributed under the terms and conditions of the Creative Commons Attribution (CC BY) license (https:// creativecommons.org/licenses/by/ $4.0 /)$.

\begin{abstract}
Sophomore students from the Chemical Engineering undergraduate Degree at the University of Salamanca are involved in a Mathematics course during the third semester and in an Engineering Thermodynamics course during the fourth one. When they participate in the latter they are already familiar with mathematical software and mathematical concepts about numerical methods, including non-linear equations, interpolation or differential equations. We have focused this study on the way engineering students learn Mathematics and Engineering Thermodynamics. As students use to learn each matter separately and do not associate Mathematics and Physics, they separate each matter into different and independent compartments. We have proposed an experience to increase the interrelationship between different subjects, to promote transversal skills, and to make the subjects closer to real work. The satisfactory results of the experience are exposed in this work. Moreover, we have analyzed the results obtained in both courses during the academic year 2018-2019. We found that there is a relation between both courses and student's final marks do not depend on the course.
\end{abstract}

Keywords: competency-based learning; mathematics skills; computer-based problem solving; engineering degrees

\section{Introduction}

Chemical Engineers are professionals capable of developing their work through innovation and continuous improvement of processes and products. This is associated with analytical, creative, and critical thinking, entrepreneurial spirit, and the ability to lead highly productive teams. In their professional performance they will have to plan, analyze and interpret, design, implement, evaluate, investigate, and put into practice possible solutions to needs that arise in society [1]. All these skills are also essential for other engineering degrees and majors [2]. This work is focused on Chemical Engineering undergraduate Degree but the objectives, procedures, and methodology could be easily applied to other engineering specialties.

Traditionally, in engineering area, there has been a mismatch between the way in which universities have evaluated the results of their educational processes in Mathematics and other subjects and the way in which society, in general, and companies, in particular, do so. We could say that until a few years ago, university teachers wanted to determine a student's level of understanding, but nowadays this has changed and now we focus on what skills and competencies they acquire during their university studies. Competenciesbased assessment seeks to change the educational process towards this direction [3]. 
Competencies-based learning is one remarkable change that the Bologna Process have brought. The European Higher Education Area implies a way of teaching and learning where competencies represent the central axis of the new system. This means that it is no longer enough for a student to learn technical or specific contents. In this framework, students must also acquire a series of competencies that guarantee that they are capable of effectively and adequately engaging in the work for which they are prepared. In any case, specific contents are of course still necessary and essential, although they acquire a practical and applicable nature [4].

The definition of competencies arises from the need to understand an increasingly diverse and interconnected environment. Individuals need to master technologies and manage huge amounts of information. In these contexts, the competencies that individuals need to achieve their goals have become more complex, requiring greater mastery of certain skills [5]. Based on the need for university students to acquire competencies, teachers must adapt to the teaching-learning processes [6].

This is the reason why teachers at the University of Salamanca, who teach Mathematics III and Engineering Thermodynamics in the second year of the Chemical Engineering Degree, in consecutive semesters, participate in this study. So, the methodology regarding the acquisition of competencies carried out in Mathematics has an explicit continuation in Engineering Thermodynamics, enriching the teaching-learning process of both courses. Obviously, coordination among all the teachers who tutor the same grade is essential, but it is particularly basic in the coordination in subjects such as Mathematics and Physics. It is not necessary to justify this collaboration, since the need for mathematics as a language to express relationships in Physics and the need of several Physics topics to apply mathematics to engineering concepts is evident. Within the sphere of Physics, there are studies that analyze the elements that influence thermodynamic learning at the university level, and they show the advantages of establishing collaborations between teachers of mathematics, physics, and engineering, that is, collaborations among different disciplines [7,8]. The researchers that present this study have a lengthy experience in teaching Physics and Mathematics (20 and 14 years, respectively). We have appreciated that each teacher (from different backgrounds) use different names for the same things, e.g., for the calculation of vibration frequencies and modes in a system, mechanics teachers do not tell students about eigenvalues or eigenvectors. A similar situation could be found in the use of the finite element method (FEM) for fracture problems. In this case, there is no partial differential equation, but the FEM is used to simulate the behavior of the material.

Furthermore, there are serious difficulties in teaching mathematics to engineering students. These students often face difficulties in learning mathematical content, in acquiring mathematical competencies, and ultimately, in being proficient in mathematics. When we teach our engineering students subjects like calculus, linear algebra, numerical methods, etc., one of our main concerns is usually how we can motivate them to learn mathematics. Engineering students often do not catch the relationship between mathematics and other subjects, such as electricity, mechanics, mechanisms, automation, electronics, or thermodynamics $[3,8]$. When students from engineering courses find the connection between topics from different subjects, they are more motivated [9]. With this proposal, we try to make students aware that mathematical tools are useful to solve engineering thermodynamic problems.

Bloom's taxonomy (BT) is used to classify learning strategies. This taxonomy establishes the learning objectives, that is, it identifies the knowledge and skills that the student must acquire. Furthermore, these strategies will not have the same difficulty, hence they are represented by a pyramid (Figure 1) that shows an increasing order complexity. The ascending order of Bloom's taxonomy is logical, since a concept cannot be understood if it is not remembered, it cannot be applied if it has not been understood, and it cannot be analyzed if it is not known where or how to put it into practice. In the 90s, nouns were replaced by verbs, and indeed, the position of the evaluation was changed, since it was considered that the highest level of difficulty is to create. Figure 1 presents both Bloom's taxonomy and the 
revised Bloom's taxonomy [10]. The challenge then, is to propose activities to the students that cover different levels within Bloom's taxonomy.

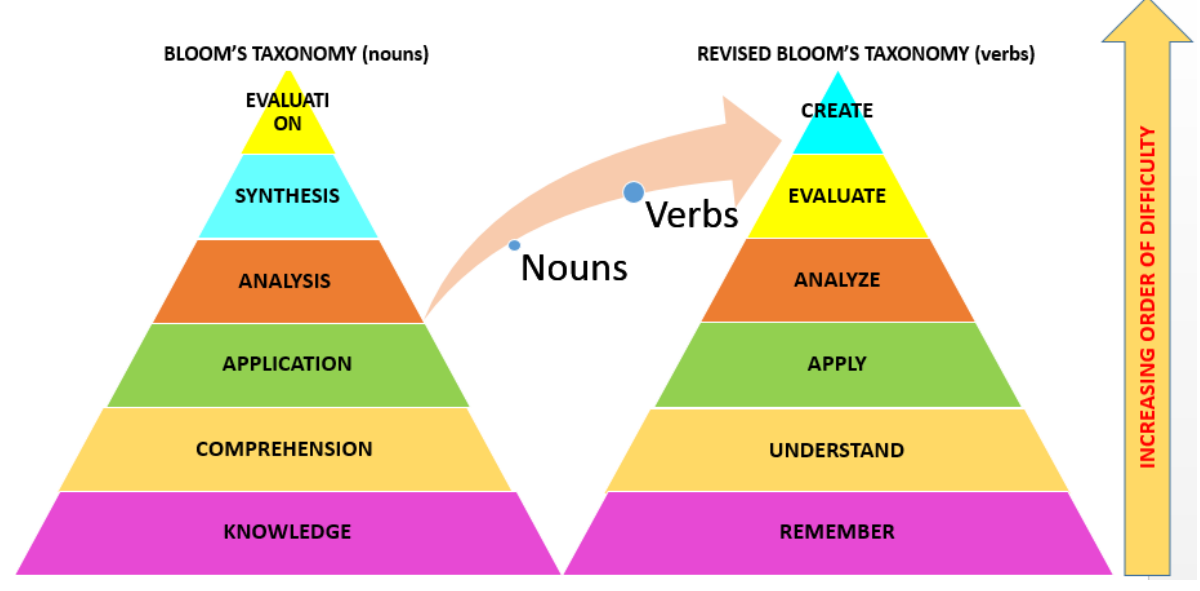

Figure 1. Comparison between Bloom's taxonomy and revised Bloom's taxonomy.

From a different perspective, the use of the computer is of special relevance in science and engineering courses. Today, it is difficult to understand laboratory data processing without computational support. In the same way, different programs allow solving mathematics and engineering thermodynamics problems much more efficiently; similar to an engineer's real-world experience. Our objective along this line is that students may know how to use mathematical tools to formulate and solve problems that arise in other subjects, more specifically in engineering thermodynamics. It is generally accepted that computer-based (or computer-enhanced) problem solving is a very important application of the computer in engineering education and practice [11-14]. The Wolfram Mathematica package is a suitable tool for solving mathematical problems. The use of symbolic software packages has been steadily rising in academic instruction and specifically in mathematics, and this trend is likely to gain strength in the upcoming years. There are numerous publications that reveal various applications of Mathematica for engineer training [9]. Moreover, for instance, interesting works were developed in the field of chemical engineering $[15,16]$.

With all the arguments explained above, during the last two courses, we have organized a project in which students of Mathematics III (essentially Numerical Methods) and Engineering Thermodynamics solve problems of these courses with the Mathematica program. In the third semester, in Mathematics III, as part of the training of the whole group, they carried out practices of numerical algorithms described in the theoretical classes using that software. The activity takes place in small groups in a computer room. In the fourth semester, the realization of some Engineering Thermodynamics problems with the Mathematica software has been proposed to a test group of volunteer students. During several practical sessions, outside of class time, these students (guided by the teacher) solve problems with the help of the computer. This initiative is recognized by University of Salamanca as an innovation and teaching improvement project [17]. The project has been carried out in coordination with all teachers (from physics and mathematics courses). On the other hand, it is part of the European project RULES_MATH [18], focused on competencies-based learning and assessment.

This paper is organized as follows: In Section 2 the state-of-the-art is discussed. Section 3 describes the context of the project carried out with students of the Chemical Engineering undergraduate degree. This project is encompassed within the global methodology of the Engineering Thermodynamics and Mathematics III courses. Methodology is summarized in Section 4. Some highly relevant examples of the work done are introduced in Section 5. Finally, project results, discussion, and the most significant conclusions are presented in Sections 6 and 7 respectively. 


\section{State-of-the-Art}

Pearson et al. presented a review of research on the teaching and learning of thermodynamics at the university level [7]. They consider that one of the factors that influence the success of students in learning thermodynamics, is understanding thermodynamics through concepts and mathematical representations. However, very few studies actually examine the students' understanding of mathematics in the context of thermodynamics. Pearson et al. encourage researchers and practitioners to collaborate across disciplinary lines with mathematicians, physicists, and engineers who also seek to help students understand the challenging topics in thermodynamics [7].

Carpenter et al. identified the mathematics needed by chemical engineering undergraduates to stimulate a dialog between mathematics and chemical engineering educators on this topic and to determine the most effective way of providing the necessary mathematical tools [8]. Students do not see connections between mathematical tools, concepts, principles, and their utility in engineering. Among the conclusions, it was suggested that mathematics courses be more applicable.

Ramkrishna et al. analyzed the role of mathematics in the field of chemical engineering in the second half of the 20th century [15]. They claimed that there was evidence of great interest among industrial colleagues on the use of mathematical models as a substitute for expensive experimentation. They also highlighted that the use of symbolic software such as Mathematica has been steadily rising in academic instruction of mathematics courses. This trend was likely to gain strength in the coming years. The proper use of this facility can only sustain the mathematical consciousness of the profession of chemical engineering.

Along the same lines, Carpenter et al. showed how to solve complex problems, in higher level courses, extensive use is made of programs such as MATLAB, MathCAD, Mathematica, and Polymath [8]. Moreover, they show that the use of these tools becomes necessary in solving interesting problems.

This same idea addressed by Shacham [12], who showed that it is generally accepted that computer-based (or computer-enhanced) problem solving is a very important or possibly the most important application of the computer in engineering education and practice.

Dos Santos et al. highlighted that computer skills were among the top ten skills chemical engineers should talk about. Training that, on the other hand, favors chemical engineers to take advantage of new opportunities in the digital area [14].

In Meunier's work [19], a multi-faceted instruction methodology is proposed over a sequence of second-year chemical engineering fundamental courses to foster the development of problem-solving strategies and to increase the confidence of students in their abilities to decipher problem data, to develop a proper mathematical framework, and to apply a first-principle approach to problem solving. Their survey results indicated that students perceive mathematics content as their main difficulty when solving problems.

Miller, in his article "Drawing on Mathematics and Science: Essential New Skills for the 21st Century Engineer: Solving the Problems of the 21st Century Will Require Engineers to Have a New Set of Skills and Mindsets" already highlighted the need for training engineers of our century in skills [2]. The rising complexity of the problems the world will face in the next century, and of the technologies that will be deployed to meet these challenges, will demand new qualities from the next generation of problem solvers. Today engineers need a wide range of professional skills, in addition to technical knowledge. While lists of such skills can vary, a partial inventory might include (between others) broad systems thinking and multidisciplinary thinking. Clearly, comprehensive knowledge in the natural sciences and mathematics is critical.

Against this background, we propose, as suggested, to strengthen the knowledge of Engineering Thermodynamics through the understanding and management of mathematical tools and vice versa, i.e., posing applicable mathematical problems. It should be noted that, as Pearson and Carpenter suggest, we have started working together with Physics and Mathematics teachers to enrich the training that students need in Chemical Engineering. We introduced students to the advantages of using programs such as Mathematica, both 
to deepen their understanding of subjects such as Engineering Thermodynamics, and for their professional future. In this sense, the competencies that a chemical engineer should acquire have to be considered in order to increase students' confidence in their ability to solve problems of increasing complexity (as Meunier [19] puts it).

On the other hand, Freudenthal proposed the use of mathematics to describe and understand the reality, which includes other disciplines and real phenomena. In fact, to mathematize reality was one of his main concerns [20,21]. Engineering students used to think that mathematics courses were necessary to become an engineer, but they do not usually appreciate its value. In this paper, we applied realistic mathematics education (RME) to thermodynamics, because properties such as volume, temperature, pressure, etc., and the calculus of energy or work, are real, practical situations an engineer would encounter. Moreover, "realistic" refers to daily life, professional, or imagined situations [22].

As was established by Werner and Mogens, mathematics instruction has two different objectives, one is related to the subject of mathematics and provides students with mathematical knowledge and competencies. The second one is related to other subjects, different from mathematics. In this case, mathematics will be integrated into other subjects and act as a tool to solve engineering problems [23]. These authors propose the use of computers as a tool for solving numerical or algebraic calculations, and to draw graphs. Furthermore, Werner and Mogens suggested six different approaches for mathematics instruction: (1) Separation, i.e., a modular system with different courses for different topics; (2) The mathematics curriculum is divided into two compartments ("pure" and "applied" mathematics); (3) Mathematics instruction includes some parts (called "islands") of applied mathematics; (4) Mixed approach with "pure" and "applied" mathematics; (5) Integrated in the curriculum; (6) the interdisciplinary integrated approach with a full integration between mathematical and non-mathematical activities, organized as a separate subject.

\section{Context}

The number of new students entering the Chemical Engineering undergraduate Degree at the University of Salamanca each academic year is between 60 and 70. Chemical engineering belongs to the Industrial Engineering area and it is a regulated profession. It is governed by the Order CIN/351/2009, of February 9, 2009, by the Ministry of Science and Innovation from the Spanish government. The curriculum lasts four years $(60$ credits per year to complete 240). Adequate training in this scientific field involves the acquisition of the basic knowledge and competencies that guarantee that a student is educated and to be able to develop the design of processes and products that are characteristic of the chemical industry and the multiple sectors related to it (pharmaceutical, biotechnology, energy, food, environmental, etc.) $[8,15]$.

In this project, we focused on the following competencies established in the curriculum of the Chemical Engineering Degree [24] (some real problems in which the different competencies are worked on are detailed in this paper). These competencies are regulated by a Spanish national law and they relate to both Mathematics and Engineering Thermodynamics (the abbreviations correspond to the academic guide).

- $\quad$ Transversal skills (T):

1. Computer knowledge in the field of study (TI5).

2. Solve problems (TI8).

3. Critical thinking (TP8).

4. Ability to apply knowledge in practice (TS1).

- $\quad$ Specific skills (S):

1. Ability to solve mathematical problems that may arise in Chemical Engineering, applying knowledge of Algebra, Geometry, Calculus, Numerical Methods, Statistics, and Optimization (DB1).

2. Basic knowledge on the use of computers, programming, operating systems, databases, and programs with engineering applications (DB3). 
3. Knowledge of the basic principles of thermodynamics and heat transmission and their application to the resolution of engineering problems (DR1).

As can be seen, the competencies that are addressed involve different levels of Bloom's taxonomy. For example, solving problems (TI8) require "remember" and "understand", critical thinking (TP8) implies "analyze", applying knowledge to different cases (TS1, DB1 and DR1) is "apply".

Mathematics III is a third semester 7.5 credits course. This course complements the basic mathematical training of the future chemical engineer with an elementary knowledge of numerical analysis, which is essential in order to translate an engineering real problem into a mathematical problem. Moreover, this subject intends to promote the capacity to solve the stated problems and to interpret the possible solutions. That is, it is intended to achieve the highest level of abstraction in Bloom's pyramid.

On the other hand, the main objective of Engineering Thermodynamics is the thermodynamic analysis of systems projected to carry out conversions among different energy sources. Among these, special attention is paid to cyclically operating devices (thermodynamic machines) designed for power generation and refrigeration. This course covers 4.5 credits in the fourth semester.

Information and Communications Technologies (ICT) help to achieve higher levels of quality in teaching and, furthermore, they allow us to mimic the skills acquired by the students required in their professional careers. The teaching of Mathematics and Engineering Thermodynamics cannot be an exception and should not be left out of the use of these tools. ICT provide students with the possibility of simulating experiences, posing very different situations, and comparing them. Sometimes, to do this manually can be difficult or at least tedious. For example, ICT allow students to understand the true scope of a problem or the effectiveness of an algorithm by analyzing the results obtained by varying hypotheses, initial conditions, etc.

The use of specific software is really useful, such as symbolic calculation packages like Wolfram Mathematica package, among others. As is generally known, these Computer Algebra Systems (CAS) have an easy syntax to learn, since the syntax and commands resemble the mathematical operations in an intuitive way and, therefore, their learning is quick and intuitive. In addition, the help they offer is comprehensive and is illustrated with numerous examples. Engineers use computers and several programs in their daily work for most of their tasks.

The University of Salamanca has a "campus" license for Mathematica, which gives legal coverage and allows installation in the computer rooms and personal computers, and is used by the entire university community. Particularly, it is installed on all computers across all four computer rooms in the Chemical Sciences Faculty. It is widely used in several undergraduate and master degrees. This program is an excellent CAS to carry out computer practices in different subjects.

\section{Methodology}

During a typical Engineering Thermodynamics or Mathematics III course, different methodological resources are used:

- $\quad$ Part of the training is given as theory lectures. Videos and mobile devices are used to enrich these sessions, which help to clarify the concepts and allow addressing experiences that otherwise would be difficult to carry out.

- An essential complement to theoretical classes are the problem resolutions in seminars. Facing problems and trying to solve them students can apply the knowledge acquired in theoretical classes and improve their competencies and skills.

- A third component is individual work, which are developed by the students: not all the proposed problems are solved during classes, therefore, students are asked to make two or three deliveries, throughout the course, with problems in which they work out individually. These tasks contribute to the ongoing assessment of the student. 
- Because of bureaucratic issues in the developing of the official university program of the course, no practical laboratory hours were established for Engineering Thermodynamics. However, we consider that it would be a really enriching complement for the in-depth understanding of the thermodynamic cycles that are addressed. For this reason, some seminars are dedicated to take students to the Thermodynamics laboratory, for example to observe the operation of a Stirling engine, for didactic purposes, as well as to experimentally measure cycle performance, maximum and minimum temperatures, and to analyze the pressure vs. volume diagram, among other aspects.

- Personal attention to students through face-to-face tutoring is essential to solve questions and doubts. In this way, we facilitate students to deepen their knowledge, while reinforcing direct and personal contact with teacher.

- An important aspect of the methodology is competencies-based assessment. This evaluation includes not only to prove that students understand the knowledge of Engineering Thermodynamics or Mathematics, but also knowing how to apply them in a professional way. That is why students (from Engineering Thermodynamics) can use class notes on written exams. This includes tests with theoretical and numerical problems to solve.

- Finally, as was mentioned before, the use of a CAS is a methodology of these courses. In the case of Mathematics, 10 hours are scheduled as mandatory activity. But, on the other hand, the use of a CAS in Engineering Thermodynamics course is designed as optional activity during some seminars along the semester.

The use of the Moodle-based Studium platform of the University of Salamanca is proposed for the different courses, both to make notes presentations and figures used in class, available to students, and also to propose problems, and to enrich the teachinglearning process through forums, experience videos, etc.

An extra activity was planned for the last two academic years: the realization of problems using the Mathematica tool. Briefly, the main objective was to allow the student a direct interaction with the topics developed during classes and with those previously worked out in mathematics subjects. The display of the results "in real time" and using all possible graphic resources is very effective in capturing the interest of the students. Moreover, computer practice familiarizes students with a working method that, undoubtedly, will be essential in the development of their professional activity.

\section{The Use of a CAS in Mathematics and Engineering Thermodynamics}

Chemical Engineering Degree students take a Computer Science course in the second semester so they are familiar with symbolic calculations packages. Sophomore students attend the Mathematics III course during the fall semester of the second year (third semester of their training). This is a mandatory course and it includes several computer classes. One of the aims of this Mathematics course is to solve problems related to theoretical content with Wolfram Mathematica. These sessions are carried out in small groups (computer rooms usually have capacity for 15-20 students).

In addition to the numerical methods described during theoretical lectures, several problems that connect students to their reality are also stated. They reveal the real usefulness of mathematics courses, as RME includes problems that students could imagine such as different situations that may arise while playing games. As an example, we present the problem of the Angry Birds (AB) game: to launch birds with parabolic trajectories. The use of games is a daily activity developed by university students and this allows them to easily know how a game works. A video game could present a real situation, and a problem in this context is sometimes easier to understand than a more elaborate one. Moreover, the same physics problem could be found in a virtual laboratory such as the projectile motion at the PhET Interactive Simulations platform [25]. 


\subsection{Angry Birds Problem to Learn Mathematics}

The Angry Birds game, developed by Rovio Entertainment Corporation, consists in destroying structures of different materials in order to eliminate the pigs inside or around them (green images in Figure 2). With the help of a slingshot, the player launches an angry bird (in red) with the angle and strength necessary to achieve the proposed objective. To avoid a tower collision and to reach its destination, the bird must pass as close to the first two towers as possible, but without touching them (see Figure 2).

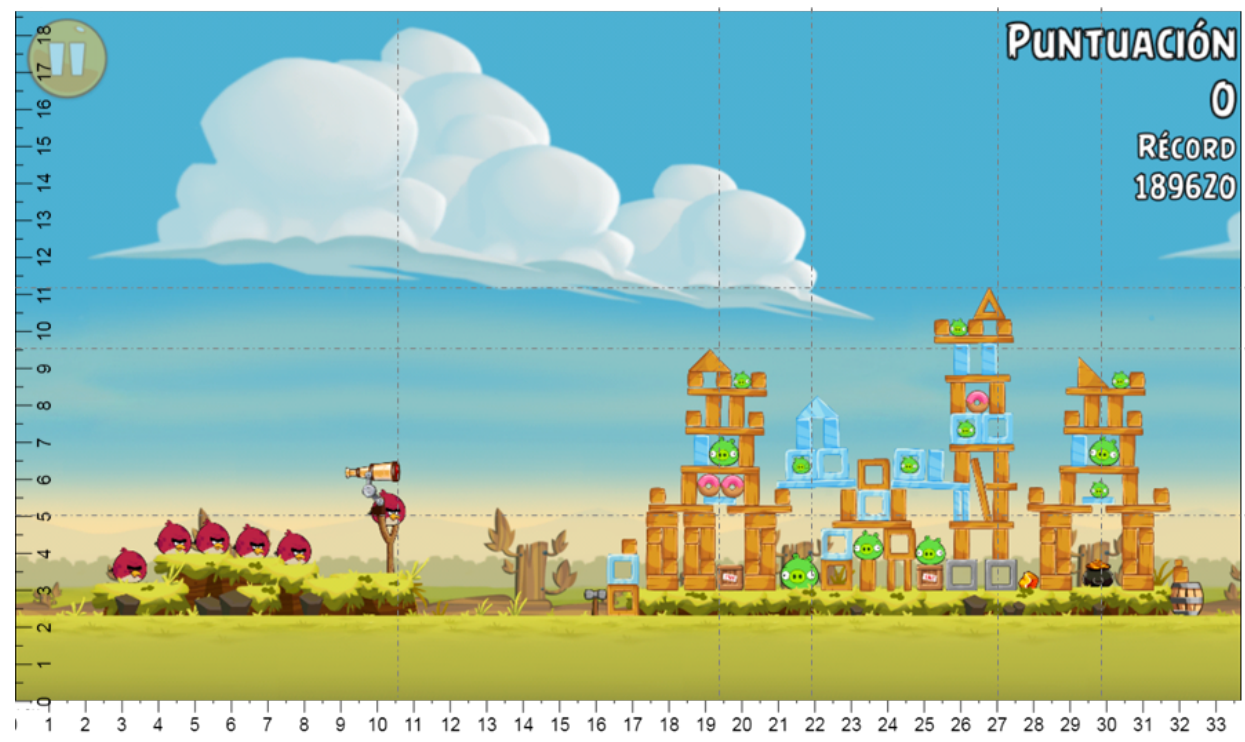

Figure 2. Image of the Angry Birds problem.

During the Academic year 2018-2019, we proposed that students undergo a written exam (from the first part of the course) that contains four questions, three of which were related to the $\mathrm{AB}$ game and Figure 2:

1. Suppose we want to hit the last tower (the one on the right). Obtain the function that gives the trajectory described by the Angry Bird in the shot and draw on the figure the points that you use.

2. Using the method of least squares adjustment to a second-degree function, obtain the polynomial that corresponds to the points used in the previous section.

3. Suppose we want to hang a curtain from tower 1 to tower 2 in the Angry Birds game. Explain in detail how you could obtain the necessary surface of fabric that we would need (approximately). What method would you choose and why?

Engineering students usually do not like this kind of task because they prefer a more "classical" statement such as, for example, obtain the interpolating polynomial for points $(10.5,5),(27,12)$, and $(31,9.5)$. From our point of view this is due to the fact that students are asked for a higher task within Bloom's taxonomy, since to solve this problem it is necessary to understand, analyze, apply, and create. Therefore, we suggested this different proposal to make them think in a different way and to acquire the required competencies. Some of the results that we found with this proposal were:

- Only $15 \%$ of the students chose to obtain the interpolating polynomial with three points, which is enough to find a parabolic trajectory. The rest of students were distributed as follows: $57 \%$ chose four points, and $19 \%$ and $6.5 \%$ chose five and six points, respectively. The remaining $2 \%$, i.e., one student, chose 12 points to obtain the trajectory. This student thought that the more points he selects, the better the function.

- $\quad$ All students have attended and passed the basic physics course, which belongs to the first semester of the Degree, so all of them have already calculated a parabolic trajectory. This is proof of compartmental education, i.e., the students used to sepa- 
rate subjects and not think about physics or mechanics in Mathematics classes and vice versa.

Figure 3 shows the solution of the problem using Mathematica. In this way, a simple interpolation problem acquires meaning and provides motivation when connected to a popular video game.

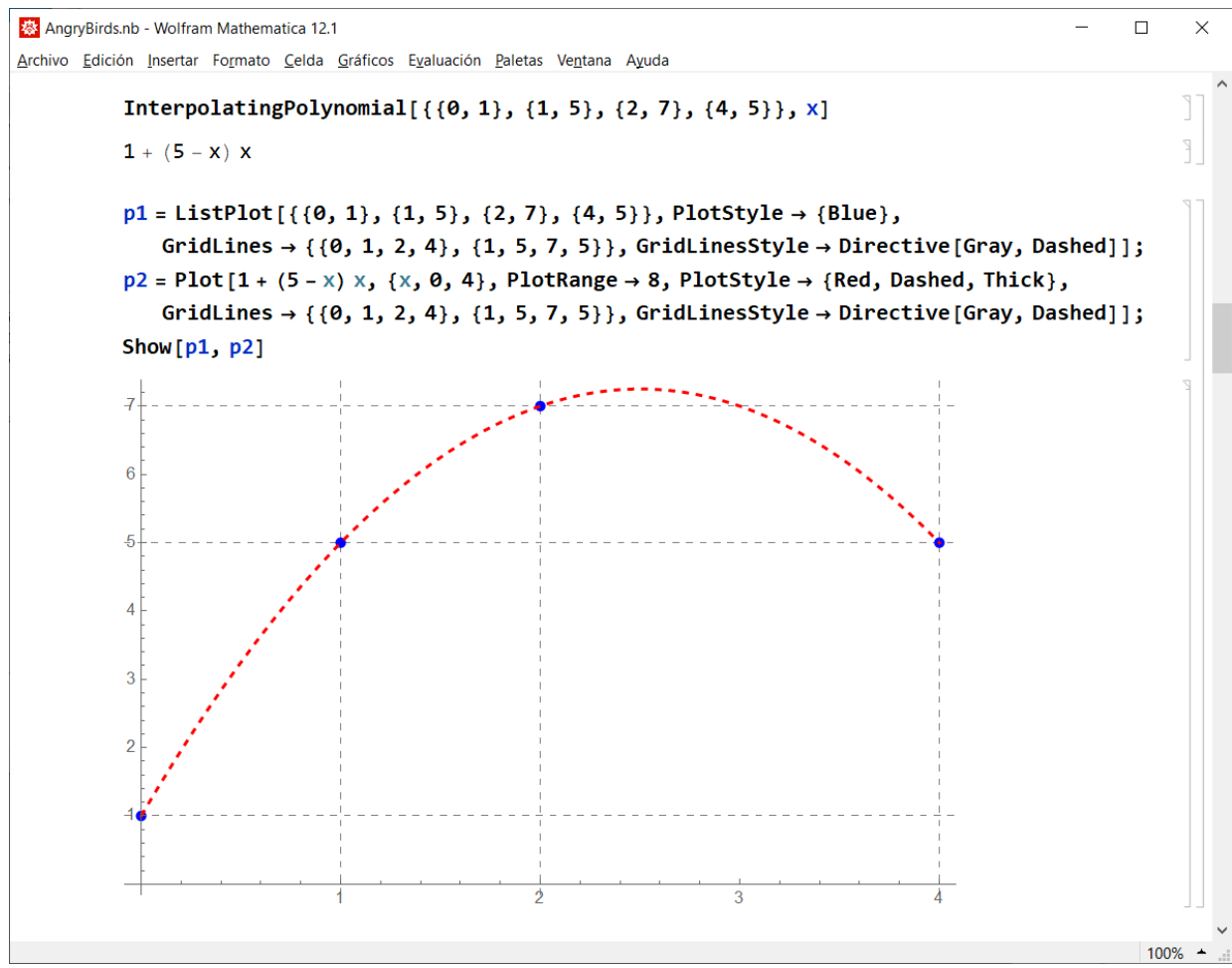

Figure 3. Angry Birds solution as an interpolation problem using Mathematica.

On the other hand, problem solving skills and computer use are being acquired, as well as the ability to put knowledge into practice. Figure 4 shows a diagram where each proposed problem (in both subjects, Mathematics III and Engineering Thermodynamics) is related to the skills being worked on. The same competencies are worked on in the two subjects. Angry Birds and Fugacity problems are solved in mathematics and the Brayton cycle in Thermodynamics (actually more problems are solved, of course, only these examples have been mentioned here). The information on each problem is detailed in later sections. 


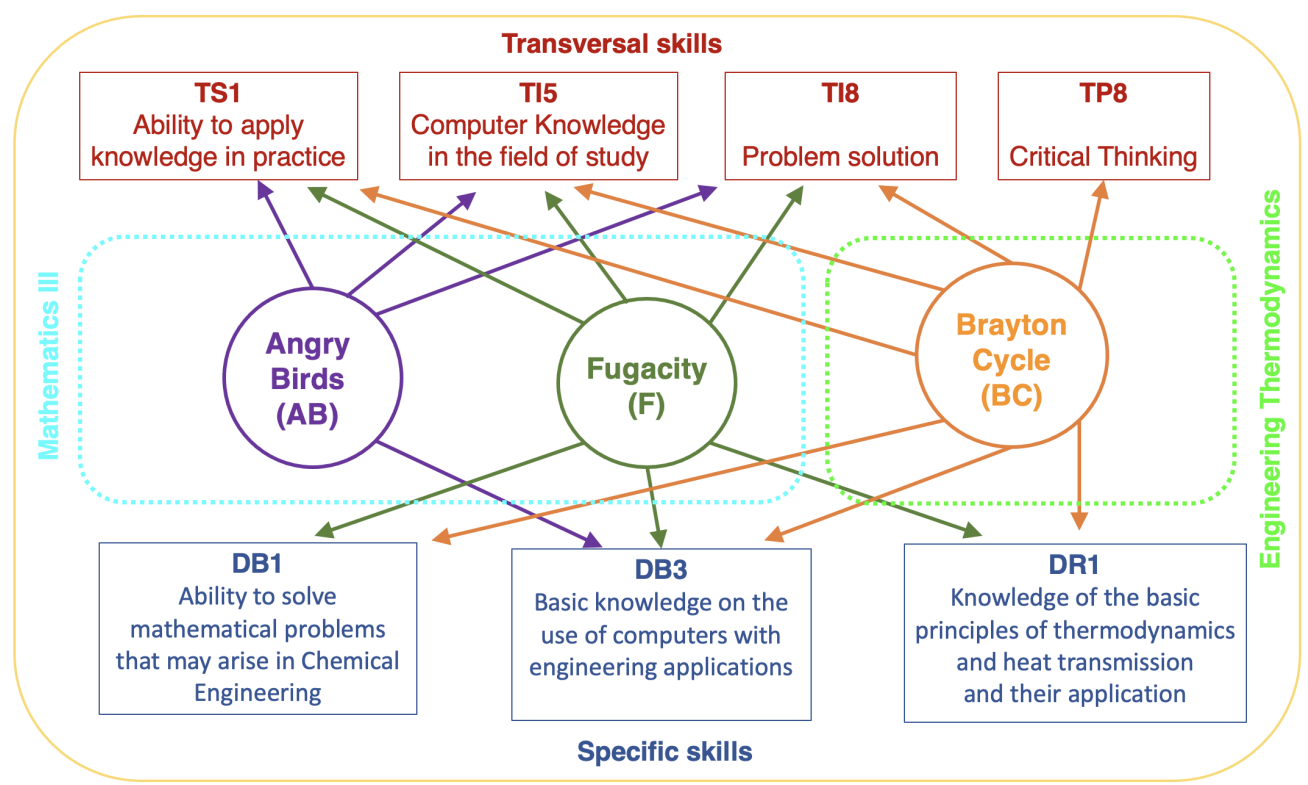

Figure 4. Relationship between the skills to be achieved and the problems using Angry Birds, Fugacity, and the Brayton Cycle. Cross-sectional skills at the top (in red) and specific skills at the bottom (in blue).

\subsection{Fugacity Problem (F)}

Within the Mathematics III lectures, as a bridge before Engineering Thermodynamics, the mathematics teacher proposes a problem to the students with thermodynamics content. As was suggested by Werner and Mogens, the use of powerful tools such as a CAS always has implications for students knowledge and competencies [23]. The proposed problem connects concepts arising in Mathematics, as the interpolation topic, with a physical problem similar to those that will be solved in the next semester in Engineering Thermodynamics. For example, the concept of Fugacity is stated as a problem:

Use the data in Table 1 to calculate $\mathrm{N}_{2}$ Fugacity at $0^{\circ} \mathrm{C}$ and $400 \mathrm{~atm}$.

Table 1. Sample of the data used by the students to solve the problem related to the concept of Fugacity.

\begin{tabular}{ccccc}
\hline$p(\mathbf{a t m})$ & 50 & 100 & 200 & 400 \\
\hline$p V / R T$ & 0.9846 & 0.9863 & 1.0365 & 1.2557 \\
\hline
\end{tabular}

To help students solve the problem using Wolfram Mathematica, the problem is broken down into the following steps (the solution of this problem is shown in Figure 5). 


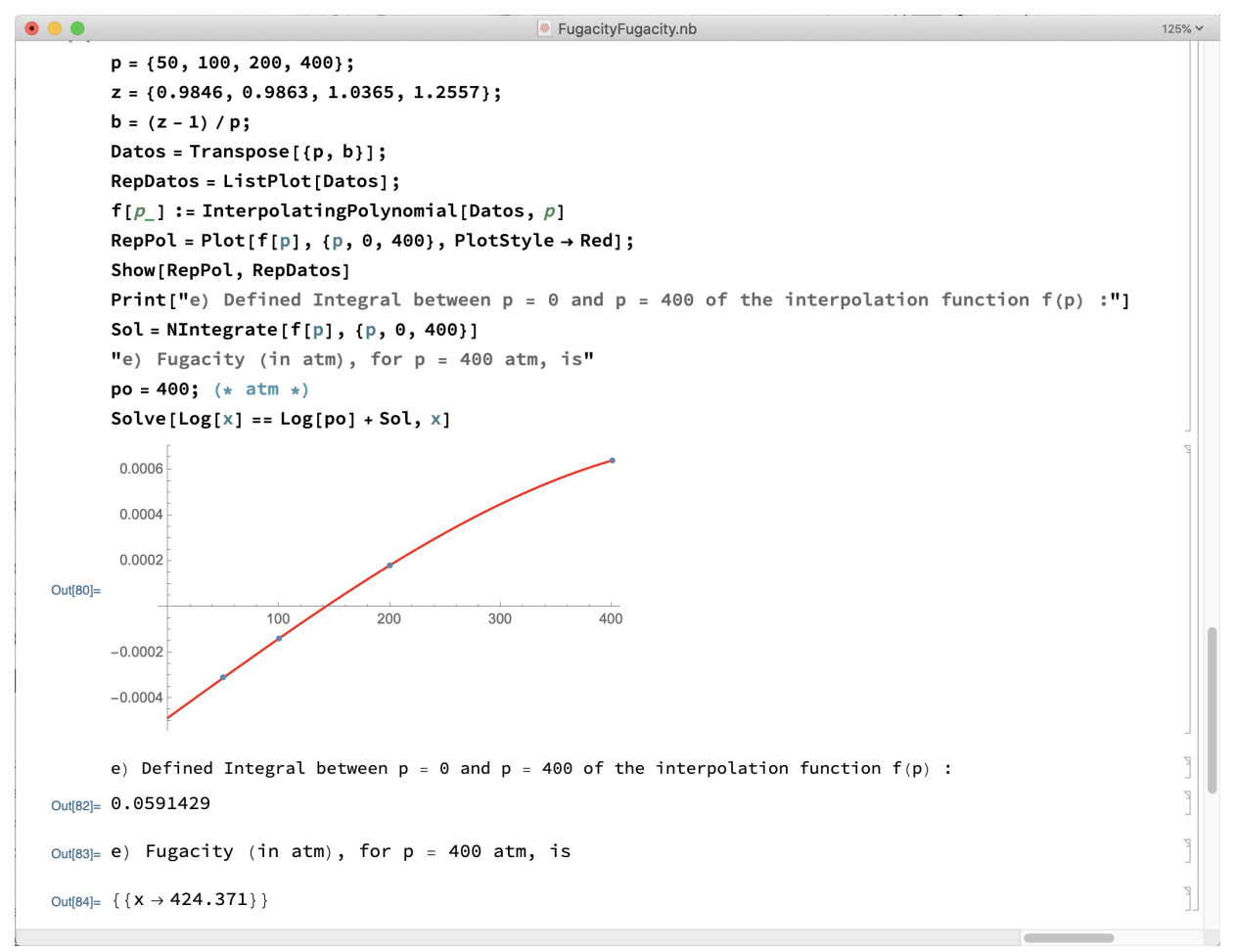

Figure 5. Fugacity solution using the Mathematica package.

The Fugacity $f$, can be calculated as:

$$
\ln f=\ln p+\int_{0}^{p}\left(\frac{V}{R T}-\frac{1}{p}\right) d p \text { or } \ln f=\ln p+\int_{0}^{p}\left(\frac{z-1}{p}\right) d p
$$

where $z=\frac{p V}{R T}$.

(a) Determine the compressibility factor values $\frac{z-1}{p}$.

(b) Make (using blue dots) the graphic representation of $\left(p, \frac{z-1}{p}\right)$.

(c) Find the interpolation polynomial that best fits these value pairs $\left(p, \frac{z-1}{p}\right)$. It shall be denoted as $f(p)$.

(d) Do represent $f(p)$ (in red color), along with the pairs of data (blue color).

(e) Determine the area under the curve between $p=0$ and $p=400$ of the function $f(p)$. As it is known, the definite integral between $p=0$ and $p=400$ of the interpolation function, $f(p)$, corresponds to the area under the curve.

(f) Clear the Fugacity, $f$, of the expression: $\ln f=\ln p+\int_{0}^{p}\left(\frac{z-1}{p}\right) d p$ where $z=\frac{p V}{R T}$.

As it can be seen in Figure 5, students use the knowledge acquired in Mathematics to solve a problem of Thermodynamics, relying on different commands and functions of the Mathematica software. It is clear which competencies are developed: ability to solve problems, using Maths and Thermodynamic knowledge, use of the computer, and applying their knowledge practically (see Figure 4).

\subsection{Brayton Cycle Problem (BC)}

One of the difficulties that Engineering Thermodynamics presents is that problems are long, and many operations are required, so the traditional problems' classes do not allow students to solve many problems in depth. However, by solving problems with the help of the computer, time is saved, allowing students to spend more time understanding the problems in depth. This is made possible by varying different magnitudes and analyzing how they affect the final solution. The powerful graphical interface of Mathematica makes this task easier. This is the reason that led us to offer students the opportunity to work on 
the problems by means of Mathematica tools. The activity was thought as voluntary for the students. During five hours outside the formally established timetable, students are told how to solve some problem samples using mathematical software. In the year 2018-2019, 5 volunteer students out of 34 participated in this activity and in the 2019-2020 academic year, 30 of 48 participated. This shows the interest that this project has gathered. Project assessment is detailed below.

A typical example solved in this specific sessions is presented below: a Brayton cycle problem. It is stated to the students as follows:

Consider a reversible air Brayton cycle (considered as ideal gas), with a mass flow of $1 \mathrm{~kg} / \mathrm{s}$ and minimum and maximum temperatures of $290 \mathrm{~K}$ and $1430 \mathrm{~K}$, respectively.

(a) Calculate the different values of pressure and temperature at each vertex of the cycle and representation of the $p-T$ diagram for different compression ratios $\left(r_{p}\right): 5,10$ and 15 .

(b) Calculation for the three cases of the compression work, the one carried out by the turbine, the absorbed heat and the thermodynamic efficiency.

(c) Repeat the exercise assuming an ideal regenerative Brayton cycle.

(d) Compare and comment on the results of sections (b) and (c). In which cases is the use of the regenerator interesting?

As mentioned before, one of the potentials of Mathematica lays on its powerful graphical capabilities, as shown in the solution to the BC problem (Figure 6). With a single image, three different situations can be identified, observing the consequences of modifying a variable in the problem, such as the particular case of the pressure relation $\left(r_{p}\right)$.

In the solutions of sections (b) and (c) of the BC problem (Figures 7 and 8), one can see how, through some simple orders, the problem is solved for several different cases. It is even possible to perform real time animations.

Results are presented in a visual and didactic way, through tables. This helps students to compare and deeply understand the root of the problem, leading them to achieve a better understanding of the physical phenomena involved [16]. This is one of the examples where all the skills initially planned, including the critical capacity (see Figure 4), are worked on, since they can tackle the same problem with multiple variants.

Another important reason for encouraging our students to learn the Mathematica software (or a similar one) is because the Degree requires the students to develop an end-of-degree project and an adequate capability is almost essential to make use of mathematical software.

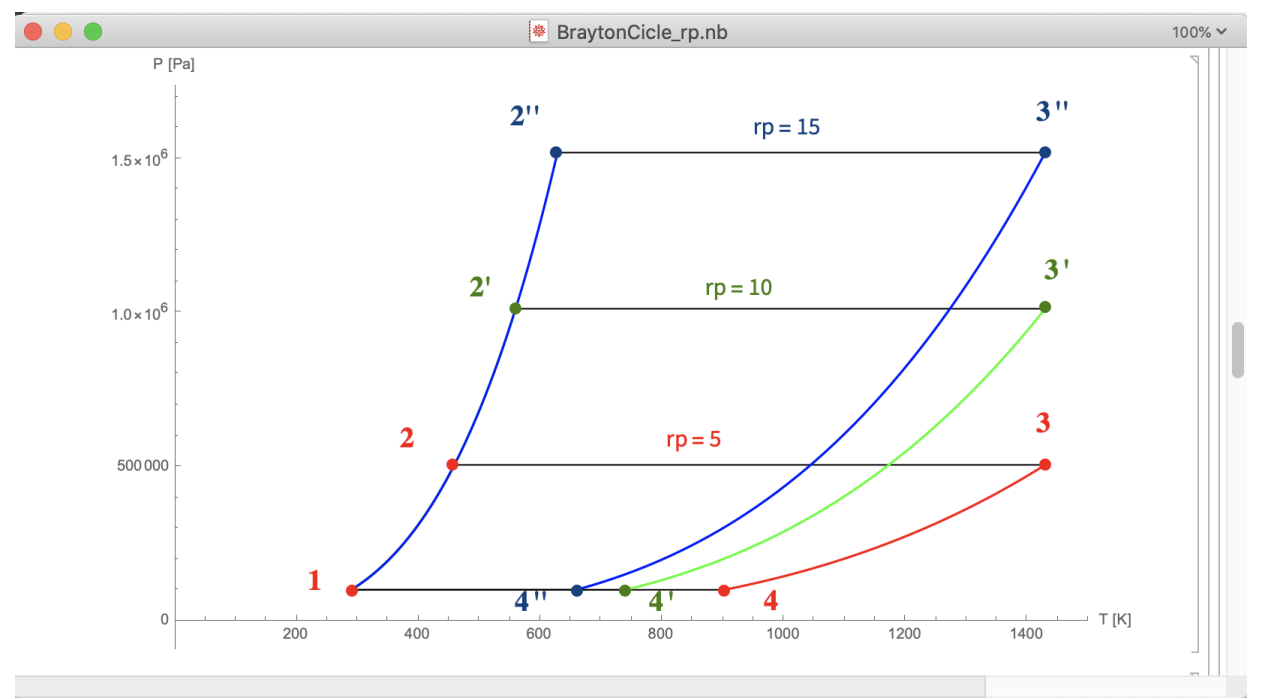

Figure 6. P-T diagram of an ideal Brayton cycle for different values of pressure ratio. Results from section (a) of the Brayton cycle problem. 


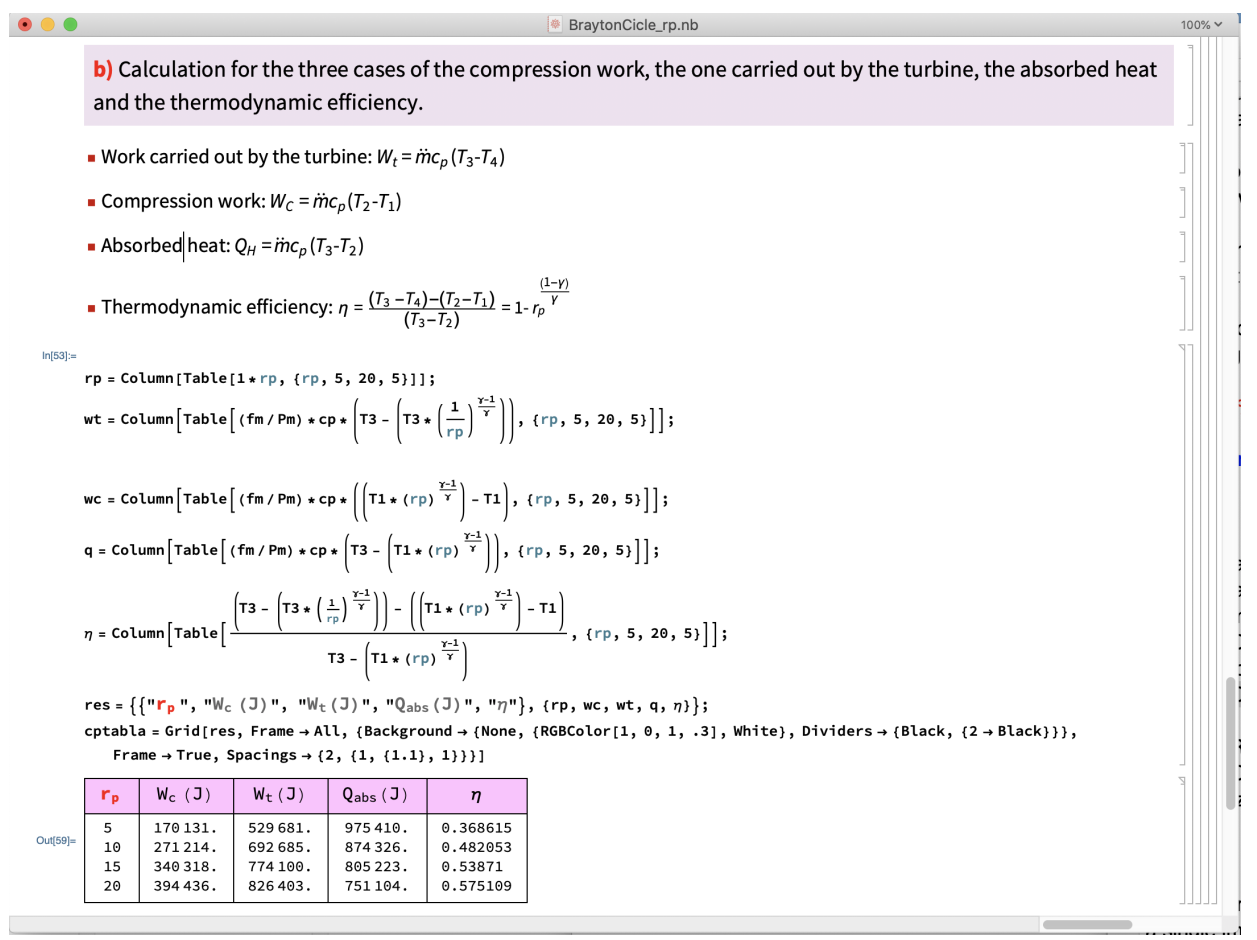

Figure 7. Results from section (b) of Brayton cycle problem. They are obtained with the Mathematica package.

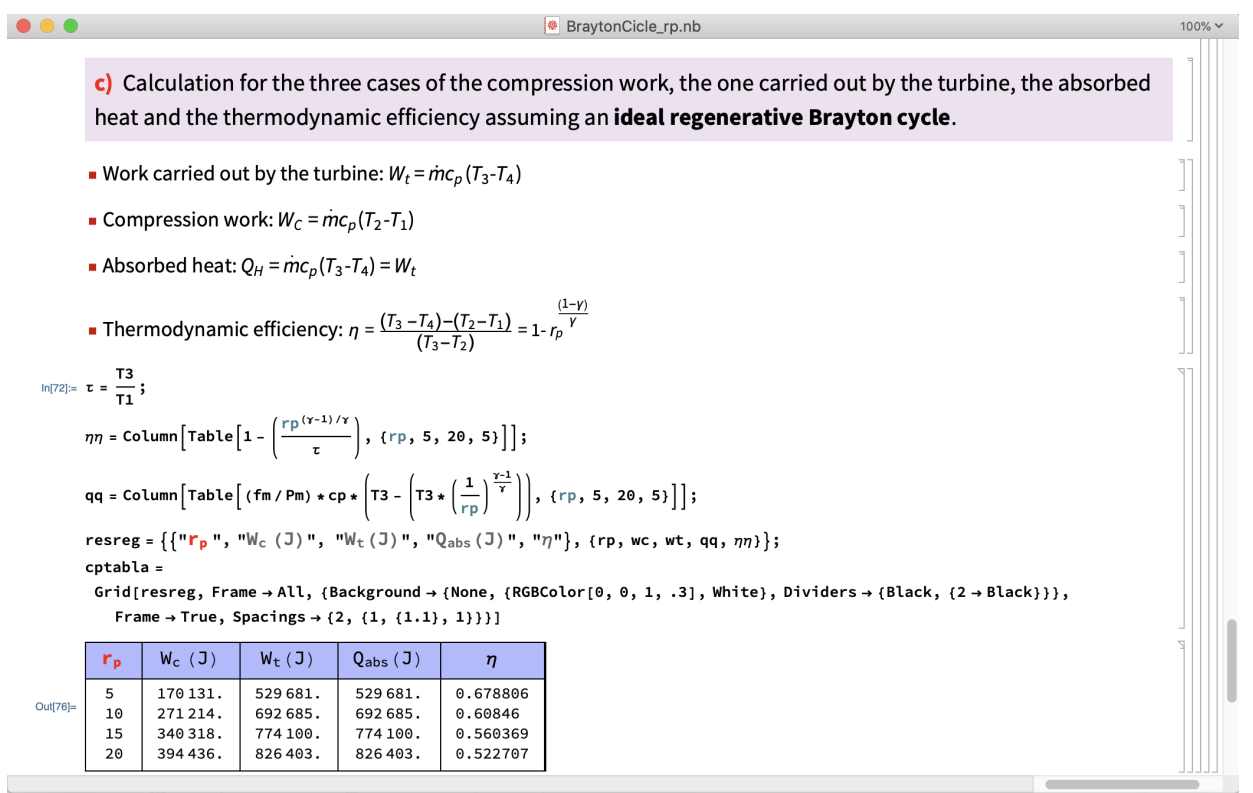

Figure 8. Results from section (c) of Brayton cycle problem.

\section{Project Results and Discussion}

With this methodology, we have included the results in Engineering Thermodynamics in the last three academic years, 2017-2018, 2018-2019, and 2019-2020, in Table 2. Although the results of 2019-2020 are really good, we concluded that they should not be taken into account for this study, since on-site classes were suspended and the entire evaluation (continuous and final) has been carried out online because of the coronavirus pandemic. "Total number of students" refers to the number of students who have enrolled in the subject of Engineering Thermodynamic. "Performance rate (over the total)" includes the students who passed the course from all those who have been enrolled. "Success rate" means the percentage of students who passed the subject with respect to those presented 
to the final exam. In the last row, the students who passed Thermodynamic Engineering from the group of students who have been involved in the project are specified, named as "Students that pass the course".

Both the success rate (percentage of students who passed the subject with respect to those presented) and the performance rate (percentage of students who pass the subject with respect to the total of enrolled students) are above $65 \%$, which can be considered good results within an Engineering Undergraduate Degree.

Table 2. Results obtained in Engineering Thermodynamics in the last three academic years: 20172018, 2018-2019, and 2019-2020.

\begin{tabular}{cccc}
\hline Academic Year & 2017-2018 & $\mathbf{2 0 1 8 - 2 0 1 9}$ & $\mathbf{2 0 1 9 - 2 0 2 0}$ \\
\hline Total number of students & 41 & 34 & 48 \\
Performance rate (of total) & $27(65.8 \%)$ & $28(82.3 \%)$ & $46(95.8 \%)$ \\
Success rate & $75 \%$ & $96.6 \%$ & $100 \%$ \\
Students involved in the project & - & $5(14.7 \%)$ & $30(62.5 \%)$ \\
Students that pass the course & - & $100 \%$ & $100 \%$ \\
\hline
\end{tabular}

It is observed that the results have improved since the beginning of the project, i.e., since academic year 2018-2019. Although there are many variables to consider, the difference between 2017-2018 and 2018-2019, from the viewpoint of the teachers responsible for the project, is a consequence of the project itself. Tutorial activities are longer and a closer relationship is established between teachers and students. Moreover, students feel especially interested in the application of new technological possibilities to their daily work.

Besides, the interest that the initiative has aroused among students has been verified: in academic year 2018-2019 only 15\% of thermodynamics students participated in this project, which rose to $63 \%$ in 2019-2020, which is a significant increase. It is remarkable that all students who have participated in the project have passed the course. It is true that, being a voluntary activity, those students who are most interested in learning generally agree to participate. The possibility of expanding it to the entire group of students enrolled in the course for future years is open.

We have collected the marks of all the students that attended the Thermodynamics ('Thermo' for short) and Mathematics ('Maths') courses and the results of a descriptive statistics analysis are shown in Table 3. When considering all marks from each course, the mean value is quite similar. In Spain, in all educational levels, the marks vary from 0 to 10 , and to pass an exam, a mark that is equal to or greater than 5 is needed. The subsequent analysis shows that the mean is different when only students that attended both courses are included.

Table 3. Descriptive statistics of Engineering Thermodynamics and Mathematics III courses (2018-2019).

\begin{tabular}{lcccccccc}
\hline & N & Range & Minimum & Maximum & Mean & Std. Deviation & Variance & Skewness \\
\hline Thermo & 31 & 8.3 & 1.0 & 9.3 & 5.335 & 1.3879 & 1.926 & -0.381 \\
\hline Maths & 57 & 8.0 & 0.0 & 8.0 & 5.472 & 2.0265 & 4.107 & -1.243 \\
\hline
\end{tabular}

We compared the results of both courses. As we have included similar activities, we suggest that these subjects might be related, because both of them are basic subjects in the undergraduate Degree and they are in the second year.

Initially, we have represented both courses marks with a Box Plot (see Figure 9) and we found that the distributions are different with different mean and median values. 


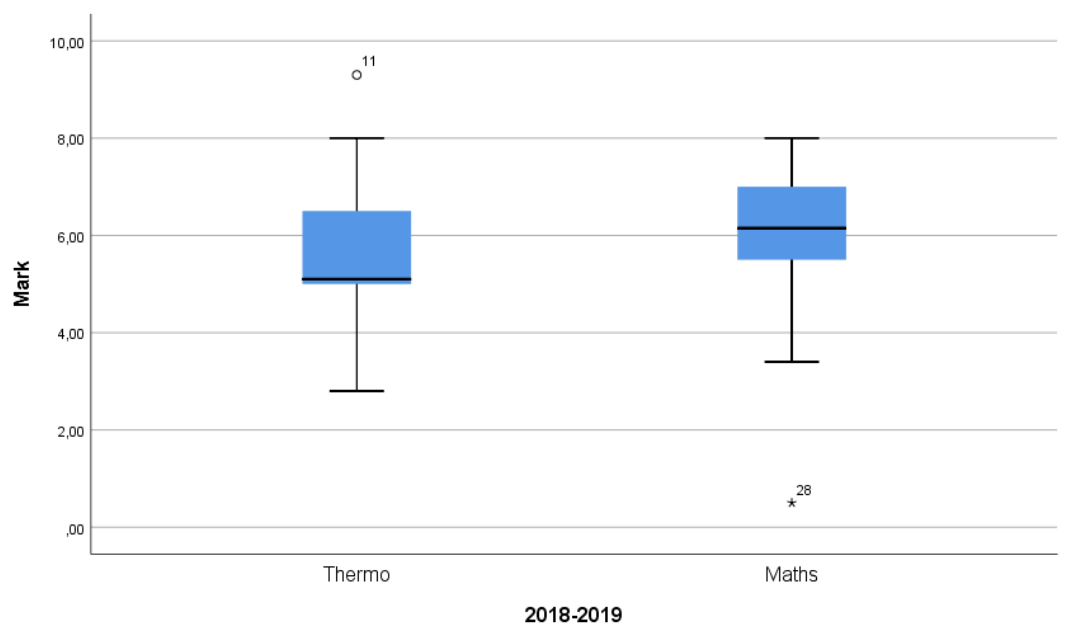

Figure 9. Box Plot graph of data from academic year 2018-2019 of students from Thermodynamic Engineering ('Thermo') and Mathematics ('Maths') courses.

From the initial 57 students in the Mathematics III course in the fall semester, only 26 of these attended the Engineering Thermodynamic course. We have analyzed these students and found that the means differ in almost 1 point (see Table 4), and the correlation between both subject' marks is -0.024 (Pearson correlation coefficient). The size of the sample in the data analysis is 23 because three students did not attend Mathematics tests.

Table 4. Paired Samples Statistics of the sample obtained with SPSS.

\begin{tabular}{lllcc}
\hline & N & Mean & Std. Deviation & Std. Error Mean \\
\hline Thermo & 23 & 5.6435 & 1.39409 & 0.29069 \\
\hline Maths & 23 & 6.5043 & 0.95939 & 0.20005 \\
\hline
\end{tabular}

Figure 10 shows the distribution of data with a histogram and the normal curve for both subjects for the academic course 2018-2019.

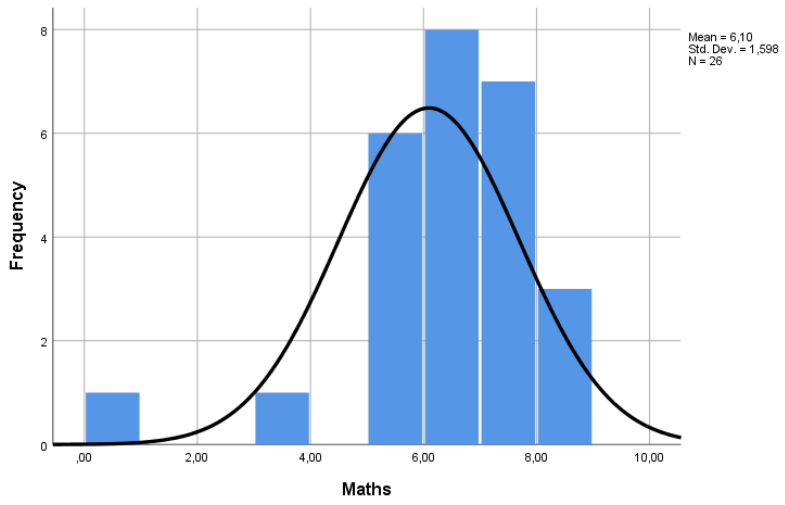

(a)

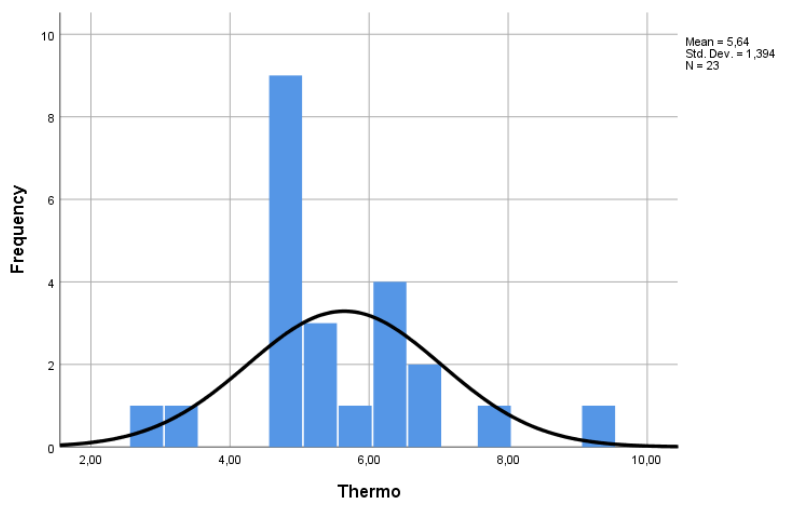

(b)

Figure 10. Histogram and the normal curve for (a) Mathematics III and (b) Engineering Thermodynamics.

After this, we normalized the data and conducted the paired-sample test, which gives a significance value of $1.00>0.05$, considering a confidence interval of $95 \%$, which indicates that we accept the null hypothesis and the mark does not depend on the subject.

In Figure 11, the marks of students have been represented. As was seen in the previous statistical analysis, students in both courses have similar behavior. 


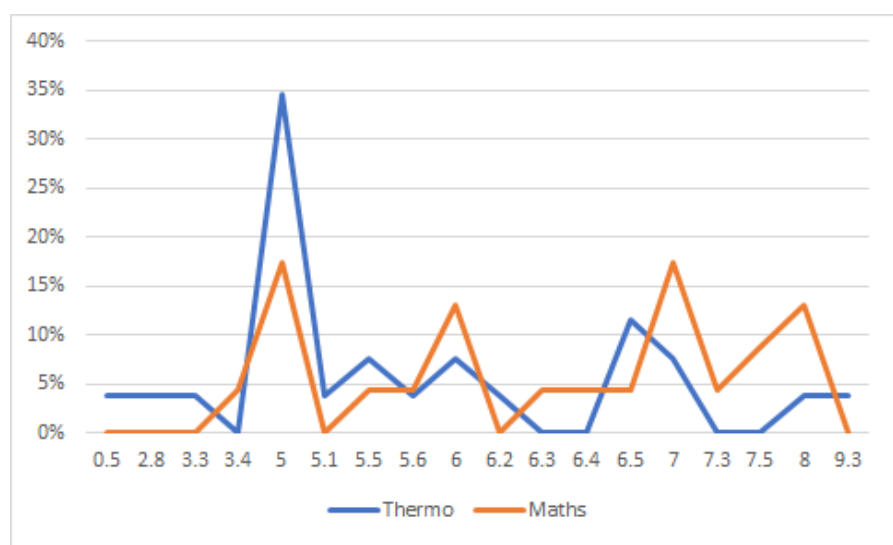

Figure 11. Graph with students marks from Thermodynamic Engineering ('Thermo') and Mathematics ('Maths') courses (2018-2019).

\section{Conclusions}

The ultimate goal of this work was to analyze sophomore students enrolled in the Chemical Engineering undergraduate Degree results. These students acquire knowledge, skills, and competencies in the use of mathematical tools through specific software and they learn to solve problems that arise in Engineering Thermodynamics with Mathematics tools. Teachers at the University of Salamanca, responsible for Mathematics III and Engineering Thermodynamics courses in successive semesters have worked together to improve the teaching and learning systems.

In the case of Engineering Thermodynamics, no software has been used prior to the academic year 2018-2019. On the basis of the results obtained since 2017-2018, we can assert that the approach proposed in this study improves students knowledge and competencies.

This work aimed to deep competencies-based learning in an engineering degree. It was focused on two specific competencies: problem solving and basic knowledge of the use of computers in engineering applications. Moreover, it was intended to introduce the students to "realistic" methods that are closer to those the graduates will use in their future careers.

First of all, in the computer practices of Mathematics III (third semester), sample problems are solved with the Mathematica software package. These examples cover both classical problems as well as others that connect students with their reality and motivate them, such as the case of the "Angry bird" game. An introductory problem related to thermodynamics is also solved in this course, i.e., the Fugacity problem.

Then, in Engineering Thermodynamics (fourth semester), students discover the application of the knowledge and competencies acquired in Mathematics by engaging in problems such as the "Brayton engine". In the project, the realization of some Engineering Thermodynamics problems through the Mathematica software was proposed to a group of volunteer students outside of class time. Project results were analyzed by the teachers of both subjects.

The interest that the initiative has aroused has been verified: in the academic year 20182019 , it was carried out with $15 \%$ of the students from the Engineering Thermodynamics class, and in the academic year 2019-2020,63\% of the students were enrolled in the project, which is a considerable increase. The global marks of the students in the subject improved considerably as a consequence of the experience. Also, class attendance improved; it was quite high compared to other subjects in the same course.

Furthermore, we have conducted a statistical analysis with data from both courses, with students only enrolled in one of them, both of them, and later with students enrolled in both courses. The result shows that the mark does not depend on the course. This indicates that with these methodology and activities we could consider joint learning, contrary to 
the more common compartmental learning. Although the mean value is different, both courses are considered similar, with a similar behavior of students between courses.

It is also noteworthy that the degree of satisfaction of the teachers involved in the project is high. On the one hand, a voluntary activity with students (carried out outside the established timetable in the case of Thermodynamics) increases their interest. On the other hand, we think that students who believe that their teachers care about their learning by implementing new methadologies will increase their awareness towards the subject and their teachers. Moreover, the project developed shows the significant advantages of a close connection and coordination between teachers from different subjects. Moreover, with this proposal, we added a new mathematical approach where two subjects share problems and methodologies, which is not common in university context.

Due to the Coronavirus COVID-19 pandemic, the analysis of data from the 20192020 academic year could not be considered, as it affected Thermodynamic course in the fourth semester.

Author Contributions: Conceptualization, M.J.S. and A.M.; methodology, M.J.S.; software, J.M.M.R.; validation, M.J.S., A.M., J.M.M.R. and A.Q.-D.; investigation, M.J.S., A.M., J.M.M.R. and A.Q.-D.; writing—original draft preparation, M.J.S. and A.M.; writing—review and editing, M.J.S., A.M., J.M.M.R. and A.Q.-D.; funding acquisition, A.M. and J.M.M.R. All authors have read and agreed to the published version of the manuscript.

Funding: This research received no external funding.

Institutional Review Board Statement: Not applicable.

Informed Consent Statement: Not applicable.

Conflicts of Interest: The authors declare no conflict of interest.

Abbreviations
The following abbreviations are used in this manuscript:
FEM

\section{References}

1. Niss, M. Mathematical competencies and the learning of mathematics: The Danish KOM project. In Proceedings of the 3rd Mediterranean Conference on Mathematical Education, Athens, Greece, 3-5 January 2003; pp. 115-124.

2. Miller, R.K. Building on Math and Science: The New Essential Skills for the 21st-Century Engineer: Solving the problems of the 21st century will require that engineers have a new set of skills and mindsets. Res. Technol. Manag. 2017, 60, 53-56. [CrossRef]

3. Queiruga-Dios, A.; Santos, M.; Bullón, J.; Martín-Vaquero, J.; Hernández-Encinas, A.; Gocheva-Ilieva, S.; Demlova, M.; Rasteiro, D.; Caridade, C.; Gayoso-Martínez, V. Evaluating engineering competencies: A new paradigm. In Proceedings of the 2018 IEEE Global Engineering Education Conference (EDUCON), Santa Cruz de Tenerife, Spain, 17-20 April 2018; pp. $2052-2055$.

4. Montero Curiel, M. El Proceso de Bolonia y las Nuevas Competencias. Tejuelo Didáctica Leng. Lit. Educ. 2010, 9, $19-37$.

5. Rychen, D.; Salganik, L. Key Competencies for a Successful Life and Well-Functioning Society; Hogrefe Publishing: Cambridge, MA, USA, 2003.

6. Rasteiro, D.; Gayoso, V.; Caridade, C.; Martín-Vaquero, J.; Queiruga-Dios, A. Changing teaching: Competencies versus contents. In Proceedings of the 2018 IEEE Global Engineering Education Conference (EDUCON), Santa Cruz de Tenerife, Spain, 17-20 April 2018; pp. 1761-1765.

7. Pearson, K.; Moon, A.; Mack, M.; Towns, M. A review of research on the teaching and learning of thermodynamics at the university level. Chem. Educ. Res. Pract. 2014, 15, 320-335.

8. Carpenter, J.; Cutlip, M.; Graham, M.; Pintar, A.; Puszynski, J. Mathematics and Chemical Engineering Education. Age Ageing 2001, 6, 1 . 
9. Queiruga Dios, A.; Hernández-Encinas, A.; Martín-Vaquero, J.; Martín del Rey, A.; Bullón, J.; Rodríguez, G. How engineers deal with mathematics solving differential equation. Procedia Comput. Sci. 2015, 51, 1977-1985. [CrossRef]

10. Anderson, L.W.; Krathwohl, D.R. A Taxonomy for Learning, Teaching, and Assessing: A Revision of Bloom's Taxonomy of Educational Objectives; Longman: New York, NY, USA, 2001.

11. Caridade, C.M.; Encinas, A.H.; Martín-Vaquero, J.; Queiruga-Dios, A. CAS and real life problems to learn basic concepts in Linear Algebra course. Comput. Appl. Eng. Educ. 2015, 23, 567-577. [CrossRef]

12. Shacham, M. An introductory course of modeling and computation for chemical engineers. Comput. Appl. Eng. Educ. 2005, 13, 137-145. [CrossRef]

13. Ivanov, A. Decision Trees for Evaluation of Mathematical Competencies in the Higher Education: A Case Study. Mathematics 2020, 8, 748. [CrossRef]

14. dos Santos, M.T.; Vianna, A.S., Jr.; Le Roux, G.A. Programming skills in the industry 4.0: Are chemical engineering students able to face new problems? Educ. Chem. Eng. 2018, 22, 69-76. [CrossRef]

15. Ramkrishna, D.; Amundson, N. Mathematics in chemical engineering: A 50 year introspection. AIChe J. 2004, 50, 7-23. [CrossRef]

16. Rasteiro, M.; Bernardo, F.; Saraiva, P. Using Mathematica to Teach Process Units: A Distillation Case Study. Chem. Eng. Educ. 2005, 39, 116-123.

17. Queiruga-Dios, A.; Bullón, J.; Hernández-Encinas, A.; Martín del Rey, A.; Martín-Vaquero, J.; Rodríguez, G.; Santos, M. Evaluación de Competencias Matemáticas en titulaciones de Ciencias e Ingeniería. 2019. Available online: https://gredos.usal.es/bitstream/ handle/10366/140191/MID_19_027.pdf?sequence=1 (accessed on 18 January 2021).

18. Queiruga-Dios, A.; Hernández-Encinas, A.; Demlova, M.; Rasteiro, D.; Sánchez, G.; Santos, M. Rules_Math: Establishing Assessment Standards. In International Joint Conference: 12th International Conference on Computational Intelligence in Security for Information Systems (CISIS 2019) and 10th International Conference on EUropean Transnational Education (ICEUTE 2019); Springer: Cham, Switzerland, 2019; pp. 235-244.

19. Meunier, L.; Hudon, N. Translating problem statements into actionable solution procedure: Developing problem-solving skills in chemical engineering second-year students. In Proceedings of the Canadian Engineering Education Association (CEEA), Ottawa, ON, Canada, 8-12 June 2019.

20. Freudenthal, H. Didactical Phenomenology of Mathematical Structures; Reidel Publishing Company: Dordrecht, The Netherlands, 1986; Volume 1.

21. Freudenthal, H. Revisiting Mathematics Education: China Lectures; Kluwe Academic Publishers: New York, NY, USA, 2006; Volume 9.

22. Van den Heuvel-Panhuizen, M.; Drijvers, P. Realistic mathematics education. Encycl. Math. Educ. 2020, 713-717. [CrossRef]

23. Blum, W.; Niss, M. Applied mathematical problem solving, modelling, applications, and links to other subjects-State, trends and issues in mathematics instruction. Educ. Stud. Math. 1991, 22, 37-68. [CrossRef]

24. Competencies of the Degree in Chemical Engineering. University of Salamanca. 2020. Available online: https://www.usal.es/ files/Competencias(21).pdf (accessed on 18 January 2021)

25. PhET Interactive Simulations Project. University of Colorado Boulder. 2002. Available online: https://phet.colorado.edu/ (accessed on 18 January 2021). 